Case Report

\title{
Primary pure squamous cell carcinoma of breast in a young female - a rare occurrence
}

\author{
Raje $\mathrm{P}^{1}$, Bhandari $\mathrm{S}^{1}$, Gujrati $\mathrm{R}^{2}$ \\ ${ }^{I}$ Departments of Surgical Pathology and Cytology and Oncosurgery, Bombay Hospital, Indore, India. \\ ${ }^{\prime}$ Dr Sapna Bhandari, Department of Pathology, Indore, India. \\ ${ }^{2}$ Dr Rajesh Gujrati, Departmetn of Oncosurgery, Saket, Indore, India
}

\section{Keywords: \\ Squamous cell carcinoma; Carcinoma; Breast.}

\begin{abstract}
Primary squamous cell carcinoma of breast is a rare disease. Incidence for primary SCC breast is $0.04-0.1$ $\%$ of all malignancies of breast. A pure form of primary SCC breast is also described and its incidence is still less. Biologically it behaves differently and usually doesn't metastasize to lymph nodes, though distant metastasis is more common. They occur usually in elderly women. Mean age of presentation is 54 years.

We report the youngest patient so far - a 27 years old woman diagnosed initially as having fibrocystic disease and later as primary pure SCC breast. She did not have any other focus of malignancy in the body and is doing well $3-1 / 2$ years post surgery and radiotherapy.
\end{abstract}

\section{INTRODUCTION}

Squamous cell carcinoma [SCC] in breastmay originate either from epidermis, nipple or from malignant transformation of a deep-seated epidermal cyst or metaplasia in a duct or medullary carcinoma or in a phylloides tumor. ${ }^{1}$ A lesion is called primary pure SCC when it is pure squamous and no ductular or other differentiation is demonstrated. ${ }^{2-4}$ It should be the only malignancy found in breast, there should be no other primary in the body and it should not originate from skin, nipple or adnexa. Even those tumors having more than $90 \%$ squamous component but some degree of other differentiation are considered as primary but not pure. ${ }^{3}$

\section{Correspondence:}

Dr. Prakash Raje, $M D$

Departments of Surgical Pathology and Cytology and Oncosurgery

Bombay Hospital, Indore, India.

\section{CASE REPORT}

A 27 years-old-woman presented at a peripheral hospital in April 2009 with a lump in left Breast. Mammography showed a large well defined increased density lesion. Sonography showed a cystic lesion with fluid levels. Fine needle aspiration (FNA) was reported as fibrocystic disease with secondary infection. Lumpectomy revealed a fluid filled cyst. Histopathology report was fibrocystic disease. Patient reported to our surgical outpatient department in June 2009 with a recurrence. Computerised axial tomography showed a large multilobated solid cystic mass lesion. Earlier FNA and biopsy slides were not available for our review.

FNA revealed malignant cells against an inflammatory background. Multinucleated cells were also present. No 


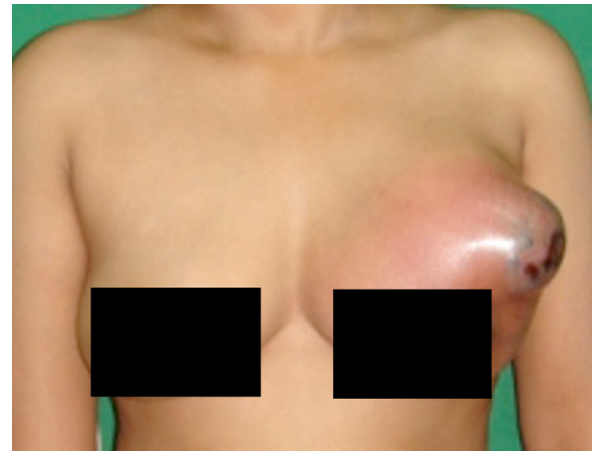

Figure 1: Photograph of the breast, huge bulging cystic mass with erythematous skin.

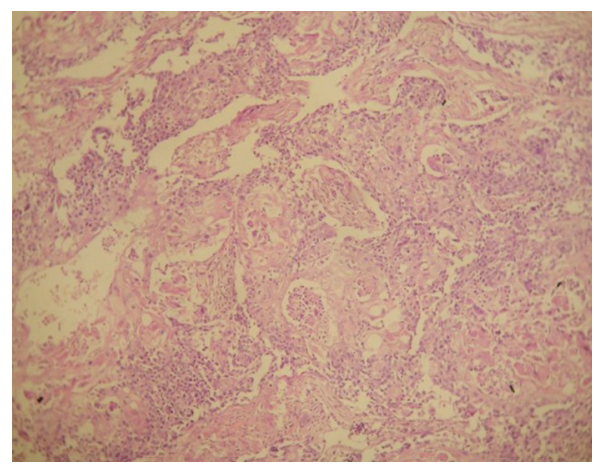

Figure 3: Low power view of tumor, many keratin pearls. No ductular differentiation. (HE stain, X100)

organoid differentiation was seen. However the type of malignancy could not be ascertained. A needle biopsy showed a malignant tumor with extensive squamoid differentiation.

Modified radical mastectomy [MRM] was done. Tumor showed large an irregular mass, $8 \times 6 \times 3 \mathrm{cms}$ having cystic spaces with areas of necrosis. Overlying skin was erythematous. Nipple and areola were not involved. Eleven lymph nodes were dissected.

Microscopically it was a pure SCC with significant pleomorphism and hyperchromasia. Keratin pearls and mitoses were many. Desmoplasia was mild. Secondary inflammation and necrosis were present.There was no vascular or lymphatic invasion. Skin, nipple and areola were free from tumor. All the lymph nodes were negative for tumor metastasis.

Extensive sampling was done subsequently to detect any ductular differentiation or in situ component but did not reveal any. Since there was no skin/adnexal lesion, no other primary in the body, no glandular/ductular differentiation and no lymph node metastasis; a diagnosis of primary pure SCC of breast was made.

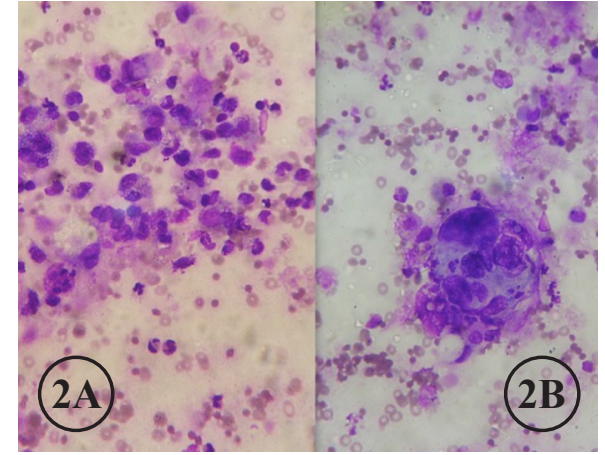

Figure $2 A$ and B: FNA smears showing malignant cells; a cluster of cells looks like squamous pearl, no ductular differentiation. (MGG stain, X100). B. (MGG stain, X400)

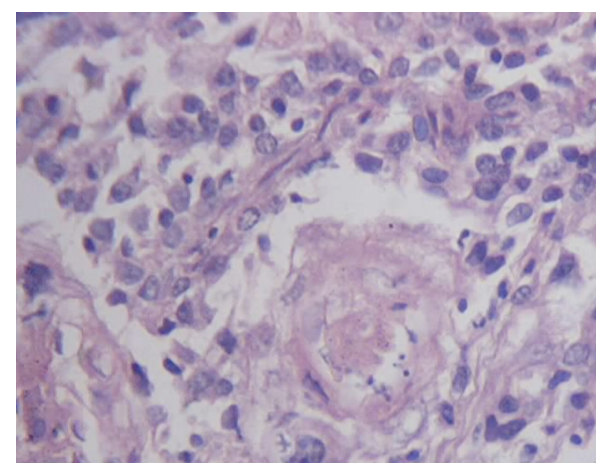

Figure 4: High power view of tumor, keratinising SCC. No ductular differentiation is seen (HE stain, X400).

Tumor was T3N0M0. Richardson Bloom grading system is not applicable in SCC.3

Immunohistochemistry for ER/PR and HER 2 neu was negative. Cytokeratin was not done.

\section{DISCUSSION}

In World Health Organisation classification 2003 primary SCCs are categorised as metaplastic carcinomas. Types of primary SCC of breast as described by Azzopardi are: ${ }^{5}$

a) Adenocarcinomashowingvaryingdegreesofsquamous differentiation,

b) Metaplastic carcinoma with squamous cells and extensive spindle cell component mimicking fibro or carcinosarcoma,

c) SCC arising in phylloides tumor and,

d) Pure SCC.

Origin of SCC in breast is believed to be an extreme form of squamous metaplasia developing in an adenocarcinoma. ${ }^{1}$ 
Squamous cell metaplasia is also seen in cysts, chronic inflammatory abscess and in adenofibromas. ${ }^{3-5}$ If these disorders evolve into carcinomas this may explain the occurrence of primary SCC in breast.

Etiology of primary pure SCC breast is unclear. A family history or genetic linkage has been suggested but not yet proven. ${ }^{6,7}$ Primary SCC of breast constitute $<0.1 \%$ of all duct carcinomas, $<0.5 \%$ of all invasive breast carcinomas and $68 \%$ of all metaplastic carcinomas. ${ }^{2,8}$ So far 100 cases have been reported - first one in 1908 by Troell et al. Only $13 \%$ of primary SCC breast are pure without some kind of glandular differentiation.

For primary SCC breast, in the series of Wargotz et el, five years disease free survival rate was $63 \% .^{2,3,9}$ Worse prognosis is reported with gestation. In view of its rarity, it is even more difficult to ascertain the prognosis of primary pure SCC. ${ }^{3}$ Primary SCC has several unique biologic characteristics; it is associated with a lower rate of lymph node metastasis at presentation $(22 \%$ vs. 40 $60 \%$ for infiltrating duct carcinoma) and a significant rate of distant metastasis. ${ }^{3-5,8}$ IHC for ER/PR receptors is usually negative. ${ }^{?}$

Duct carcinomas are known to occur at this age. However primary SCC of breast usually occurs in women 38 to 70 years of age, mean age 54 years. ${ }^{7,8}$ Youngest patient reported (by Krishna et al, 1998) was 34 years old. Our patient was 27 years old which is youngest reported so far. Breast carcinomas usually present as firm to hard painless lump. This case presented as a cystic, fluid filled, tender mass. Early in course of disease this might have mislead to a diagnosis of fibrocystic disease - clinically, cytologically and histologically.

Only few reported cases and limited work done in this area has lead to a low level of awareness among clinicians and pathologists. Existence of such an entity and possible presence of malignancy in an apparently benign disorder, especially in a young patient, emphasise the importance of thorough pathological examination of a cyst or breast abscess. Finding a malignant squamous focus should make one suspicious. If diagnosed early or on FNA, a routine axillary dissection can be avoided and substituted with a sentinel lymph node biopsy. ${ }^{10}$

There is also a need to differentiate pure primary SCC from metaplastic and metastatic carcinoma in breast because of their different biologic behaviour, line of treatment and prognosis. ${ }^{6,7,8}$

We report this case for its rarity, young age of the patient, cystic nature of the tumor, pure squamous differentiation, initial misdiagnosis and paucity of case reports and inadequate literature.

\section{REFERENCES}

1. Pricolo R, Croce P, Voltolini F, et al. Pure and primary squamous cell carcinoma of the breast. Minerva Chir 1991;46:215-9.

2. Aparicio I,Martinez A,Hernandez G, Hardisson D, De Santiago J. Squamous cell carcinoma of the breast. Eur J Obstet gynecol Reprod Biol 2008;137:222-6. CrossRef

3. Behranwala KA, Nasiri N, Abdullah N, et al. Squamous cell carcinoma of the breast: Clinicopathologic implications. Eur J Surg O ncol 2003;29:386-9. CrossRef

4. Pramesh CS, Chaturvedi P, Saklani AP, et al. Squamous cell carcinoma of breast. J Postgrad Med 2001;47:270-1.

5. Azzopardi JG. Problems in breast pathology. In: Bennington JL, editor. Major problems in pathology. 1st edn. Philadelphia: W. B. Saunders Co.; 1979. pp 277-300.

6. Fisher ER, Gregorio RM, Palekar A, et al Mucoepidermoid and squamous cell carcinoma of the breast with reference to squamous metaplasia and giant cell tumours. Am J Surg Pathol 1983;7:15-27. CrossRef

7. Cornog JL, Mobini J, Steiger E, Enterline HT. Squamous cell carcinoma of the breast. Am J Clin Pathol 1971;55:410-7.

8. Menes T, Schachter J, Morgenstern S, et al. Primary Squamous cell carcinoma of the breast. Am J Clin Oncol 2003;26:571-3. CrossRef

9. Fisher ER, Gregorio RM, Fisher B. The pathology of invasive breast cancer: a syllabus derived from the findings of the National Surgical Adjuvant Breast Project (Protocol No 4). Cancer 1975;36:1-85. CrossRef

10. Stevenson JT, Graham DJ, Khiyami A, Mansour EG. Squamous cell carcinoma of the breast: a clinical approach. Ann Surg Oncol 1996;3:367-74.CrossRef 